\title{
Birth weight and term of the gestation in pregnancies complicated by isolated oligo and isolated polyhydramnios
}

\author{
Manikanta Reddy $\mathbf{V}^{1}$, Senthil Kumar $\mathbf{S}^{1}$, Sanjeeva Reddy $\mathbf{N}^{2}$
}

\begin{abstract}
${ }^{1}$ Department of Anatomy, ${ }^{2}$ Department of Reproductive Medicine, Sri Ramachandra Medical College and Research Institute, Chennai-600116, Tamil Nadu, India
\end{abstract}

Received: 25 September 2013

Accepted: 8 October 2013

\section{*Correspondence:}

Dr. S. Senthil Kumar,

E-mail: ssksrmc@gmail.com

(C) 2013 Manikanta Reddy V et al. This is an open-access article distributed under the terms of the Creative Commons Attribution Non-Commercial License, which permits unrestricted non-commercial use, distribution, and reproduction in any medium, provided the original work is properly cited.

\section{ABSTRACT}

Background: To access the birth weight of the newborn and term of the gestation in pregnancies complicated by isolated oligo and polyhydramnios.

Methods: A Hospital based study has been conducted in the Department of Obstetrics and Gynaecology, Sri Ramachandra Medical College and Research Institute, Chennai. All the singleton pregnancies diagnosed with Isolated Oligo and Polyhydramnios were enrolled in the study. All the subjects were followed up to their delivery. Birth weight and Term of the Gestation were recorded immediately after delivery.

Results: Out of 3,567 patients $32(0.9 \%)$ and $5(0.15 \%)$ were diagnosed as Isolated Oligo and Polyhydramnios respectively.

Among $32(0.9 \%)$ newborns of Isolated Oligohydramnios, 5 (15.62\%) were Very Low Birth Weight $(\leq 1,500 \mathrm{gms}), 14$ $(43.75 \%)$ were Low Birth Weight $(1,500-2,500 \mathrm{gms})$ and $13(41 \%)$ were with normal birth weight $(2,500$ $3,800 \mathrm{gms})$. None of the cases were with Large for Gestational Age babies (> 3800gms). On the other hand Preterm and Term gestations were $17(53.12 \%)$ and 15(46.8\%) respectively in this group.

Among the $5(0.15 \%)$ cases of Isolated Polyhydramnios group, Very Low Birth Weight and Low Birth Weight newborns were $1(20 \%)$ each and newborns with normal Birth weight were $3(60 \%)$. Similarly, Preterm and Term gestations were $2(40 \%)$ and $3(60 \%)$ respectively.

Conclusion: Isolated Oligo and Polyhydramnios are associated with increased rate of Low Birth Weight (Very Low Birth Weight and Low Birth Weight) neonates and Preterm deliveries.

Keywords: Isolated oligohydramnios, Isolated polyhydramnios, Low birth weight, Pre term babies

\section{INTRODUCTION}

The term isolated Oligo and Polyhydramnios refers to the condition when Oligo and Polyhydramnios are not associated with high risk conditions of the pregnant women and fetus such as Pregnancy Induced Hypertension (PIH), Gestational Diabetes Mellitus (GDM), Premature Rupture Of Membranes (PROM), Intra Uterine Growth Retardation (IUGR), Fetal anomalies. ${ }^{1}$
In general, Oligo and Polyhydramnios are the conditions where Amniotic Fluid Index (AFI) will be $\pm 5^{2,3}$ and \pm 24 $\mathrm{cm}^{2,3}$ respectively. Multiple number of articles stating the association of Isolated Oligo and Polyhydramnios with Low Birth Weight (LBW), Macrosomia, Preterm, Increased Lower Segment Cesarean Section (LSCS), low APGAR score, NICU admission, fetal Anomalies and so on when few articles are disproving the same.

The current study has been undertaken to access the Birth Weight of the newborn and Term of the Gestation at the 
time of delivery in pregnancies complicated by Isolated Oigo and Polyhydramnios as "The Birth Weight of an infant is the single most important determinant of its chances of survival, healthy growth and development" ${ }^{\prime, 5}$. At the same time, term of the gestation is highly essential for the growth, maturity and immunological development of fetus.

\section{METHODS}

Study has been conducted in the Department of Obstetrics and Gynecology, Sri Ramachandra Medical College and research Institute, Chennai over a period of 15 months (April 2012 to June 2013).

Institutional Ethical Committee approval has been acquired for the study.

All the singleton pregnant women who scheduled for delivery with Isolated Oligo and Polyhydramnios (without GDM, PIH, PROM and Congenital Anomalies of fetus) were enrolled in the study after the informed consent. All subjects were followed up to their delivery. Birth Weight of the Newborn and Term of the Gestation at the time of the delivery were recorded.

Newborn's Birth weight $<2500$ gms is Low Birth Weight (LBW), Birth weight between 2,500 to 3,800gms has been considered as normal birth weight where as Birth weight > 3,800gms has been considered as Large for Gestational age baby (LGA). Similarly Gestational age (GA) < end of 37 weeks is Preterm and GA completed 37 weeks -42 weeks is Term and GA >completed 42 weeks is Post term. ${ }^{4}$

Data has been analyzed using SPSS 16 software.

\section{RESULTS}

Out of 3,567 patients during the study period, $32(0.9 \%)$ and $5(0.15 \%)$ were diagnosed as Isolated Oligo and Polyhydramnios respectively.

Among $32(0.9 \%)$ newborns of Isolated Oligohydramnios $5(15.62 \%)$ were less than $1,500 \mathrm{gms}$, considered as Very Low Birth Weight (VLBW), 14 (43.75\%) had birth weight between $1,500-2,500 \mathrm{gms}$ which was considered as Low Birth Weight (LBW) and $13(40.6 \%)$ were with normal birth weight i.e. between 2,500 to $3,800 \mathrm{gms}$. None of the cases were with Large for Gestational Age babies (LGA). On the other hand Preterm and Term gestations were $17(53.12 \%)$ and $15(46.8 \%)$ respectively in this group (Table 1).

Table 1: Descriptive statistics of various variable of isolated oligohydramnios group.

\begin{tabular}{|lllll|}
\hline Variable & Minimum & Maximum & Mean & Std. Deviation \\
\hline Age & 20 & 37 & 26.06 & 4.662 \\
\hline AFI & 1.0 & 5.0 & 3.994 & 1.0910 \\
\hline $\begin{array}{l}\text { Birth Weight of all Isolated } \\
\text { Oligohydramnios Babies (gms) }\end{array}$ & 1120 & 3780 & 2369.03 & 628.128 \\
\hline Birth Weight of LBW Babies (gms) & 1600 & 2469 & 2212.07 & 234.180 \\
\hline Birth Weight of VLBW Babies (gms) & 1120 & 1470 & 1320.00 & 151.162 \\
\hline $\begin{array}{l}\text { Birth Weight of Normal Birth weight } \\
\text { Babies (gms) }\end{array}$ & 2580 & 3780 & 2941.54 & 331.458 \\
\hline APGAR Score - 1 Min (Out of 10) & 5 & 8 & 7.59 & .911 \\
\hline APGAR Score - 5 Min (Out of 10) & 6 & 9 & 8.72 & .729 \\
\hline Hemoglobin (gms/dl) & 8.0 & 16.0 & 11.178 & 1.6595 \\
\hline Gestational Age (Weeks + Days) & $28+1$ & $40+6$ & $36+4$ & 3 \\
\hline
\end{tabular}

Among the $5(0.15 \%)$ cases of Isolated Polyhydramnios group, VLBW and LBW newborns were 1(20\%) each and newborns with normal Birth weight were $3(60 \%)$. Whereas Preterm and Term gestations were 2(40\%) and $3(60 \%)$ respectively.

\section{DISCUSSION}

In the present study we focused on the Birth Weight of the Newborn and the Term of Gestational Age at the time of the delivery in pregnancies complicated with Isolated Oligo and Polyhydramnios. 
In our study we found higher rate of Low Birth Weight (Includes both LBW and VLBW) neonates and Preterm deliveries than normal in both Isolated Oligo and Polyhydramnios groups.

Among the $0.9 \%$ of isolated oligohydramnios Low Birth Weight (Includes both LBW and VLBW) Vs Normal birth weight Neonates were $59.4 \%$ Vs $40.6 \%$. Similarly Preterm Vs Term Gestations were $53.1 \%$ Vs $46.1 \%$. In case of the Isolated Polyhydramnios group Low Birth Weight (Includes both LBW and VLBW) Vs Normal birth weight Neonates were $40 \%$ Vs $60 \%$ and Preterm Vs Term Gestations also occurred in $40 \%$ Vs $60 \%$.

Prevalence of Isolated Oligohydramnios has been quoted between $0.5 \%^{6}-16.86 \%^{1,7}$ in the existing studies. In the present study $0.9 \%$ (32) of cases was Isolated Oligohydramnios among 3,567 deliveries.

Our findings of Oligohydramnios group are similar to the results of Nir Melamed et $\mathrm{al}^{6}$ who conducted a retrospective cohort study in 108 preterm Isolated Oligohydromnios patients. Likewise Hima Ahmed et al. ${ }^{9}$ Locatelli A et $\mathrm{al}^{9}$ and Pershit Chate et $\mathrm{al}^{10}$ evaluated the perinatal outcome in patients with Isolated Oligohydramnios and observed increased rate of Low Birth Weight and Preterm deliveries.

In contrast to the above findings, Conway $\mathrm{DL}$ et $\mathrm{al}^{11}$ found no significant difference of Birth Weight and Term of Gestational age between the Isolated Oligohydramnios and Control group with 183 subjects in each group.

Panting - Kemp A et al $^{12}$ carried out a study with 151 singleton pregnancies of Isolated Polyhydramnios and found no significant LBW in association. Similarly Smith $\mathrm{CV}$ et $\mathrm{al}^{13}$ also didn't find the increased incidence of LBW and Preterm in the Polyhydramnios group.

Whereas in contrast to the Panting - Kemp A et al ${ }^{12}$ \& Smith $\mathrm{CV}$ et $\mathrm{al}^{13}$ findings, and in line with the present study findings Kung - Chao Chen et $\mathrm{al}^{14}$ and Dorleijn $\mathrm{DM}$ et $\mathrm{al}^{15}$ noticed the higher rate of Preterm deliveries and Low Birth Weight Newborns in the study group of Isolated Polyhydramnios.

Smith CV et al $^{13}$ found $8.2 \%$ of pregnancies complicated by Isolated Polyhydramnios in 1177 patients. He concluded Isolated Polyhydramnios is not an indication of impaired perinatal outcome.

Maliha Sadaf et $\mathrm{al}^{16}$ evaluated perinatal outcome in Explained (Polyhydramnios) and Unexplained (Isolated Polyhydramnios) Polyhydramnios and observed the increased rate of LBW and Preterm deliveries in Unexplained Polyhydramnios group, which will go with the present study findings.

In the present study, findings of Isolated Polyhydramnios group holds less importance as very less cases were recorded and none of the recorded cases underwent Lower Segment Cesarean Section (LSCS) in this group. Lower Segment Cesarean Sections (LSCS - both Emergency and Elective) were more prevalent $(n=24 ; 75 \%)$ in Isolated Oligohydramnios groups which are iatrogenic as in most of the previous studies. Among these 24 subjects delivered by LSCS, 12 (50\%) were Preterm and with LBW. Since Isolated Oligohydramnios is the condition not complicated by maternal/fetal high risk condition, we suggest the follow-up of pregnancy with maternal hydration therapy/appropriate conservation ${ }^{17,18}$ in order to increase the Amniotic Fluid Volume and to reduce LSCS (iatrogenic) before 37 weeks (Preterm) of gestational age.

\section{CONCLUSION}

Isolated Oligo and Polyhydramnios are associated with high rate of Low Birth Weight (LBW and VLBW) neonates and Preterm deliveries. Isolated Oligohydramnios holding the higher prevalence of Low Birth Weight and Preterm deliveries than Isolated Polyhydramnios group.

\section{ACKNOWLEDGEMENTS}

We would like to thank INSPIRE Division, Department of Science and Technology, Government of India, India for funding, Dr. Binu Ninan, Professor of Neonatology, Dr. S. Melani Rajendran, Dr. Rameshkumar Subramanian, Professor of Anatomy, SRMC \& RI, Dr. V. Sankar, Head I/C, Department of Anatomy, PGIBMS, Dr. Pushpalatha Baruva, Professor of Obstetrics and Gynaecology and Dr. Dinesh Kamaraj, Department of Pediatrics, SRU for their support.

Funding: INSPIRE Division, Department of Science and Technology, Government of India, India.

Conflict of Interest: None declared

Ethical Approval: Approved by the Institutional Ethical Committee, Sri Ramachandra University

\section{REFERENCES}

1. Jun Jhang, James Troendle, Susan Meikle, Mark A. Klebanoff, William F. Rayburnc. Isolated Oligohydromnios is not associated with adverse perinatal outcomes. BJOG: an International Journal of Obstetrics and Gynaecology 2004; 111:220 - 25.

2. Disorders of Amniotic Fluid. In: Cunningham, Levono, Bloom, Hauth, Rouse, Spong, eds. Williams Obstetrics. $23^{\text {rd }}$ ed. USA: Mc Graw Hill; 2010:490 - 499 .

3. Everett F. Magann, Adam T. Sandlin, Songthip T. Ounpraseuth. Amniotic Fluid and the Clinical Relevance of Sonographically Estimated Amniotic fluid Volume. Journal of Ultrasound in Medicine 2011; 30:1573-1585.

4. Preventive Medicine in Obstetrics, Paediatrics and Geriatrics. In: Park. K. Park's Textbook of Preventive and Social Medicine. $22^{\text {nd }}$ ed. Jabalpur: Banarsidas Bhanot;2011: 480 - 562. 
5. Sumithra Muthayya. Maternal Nutrition and Low birth Weight - What is really important? Indian J Med Res 2009; 130: 600 - 608 .

6. Nir Melamed, Pardo J, Milstein R, et al. Perinatal outcome in pregnancies complicated by isolated oligohydramnios diagnosed before 37 weeks of gestation. Am J Obstet Gynecol 2011;205:241.

7. Mercer LI, Brown LG, Petres RE, Messer RH. A Survey of Pregnancies complicated by decreased Amniotic fluid. Am J Obstet Gynecol 1984; 149: $335-361$.

8. Hina Ahmad, Shama Munim. Isolated Oligohydromnios is not an indicator for adverse perinatal outcome. J Pak Med Assoc October 2009; $691-694$.

9. Locatelli A, Vergani P, Toso L, Verderio M, Pezzullo JC, Ghindini A. Perinatal outcome associated with oligohydramnios in uncomplicated term pregnancies. Arch Gynecol Obstet 2004; 269: $130-3$.

10. Pershit Chate, Meena Khatri, Hariharan C. Pregnancy outcome after diagnosis of ligohydromnios at term. Int $\mathrm{J}$ Reprod Contracept Obstect Gynecol. 2013 Mar; 2 (1): 23 - 26.

11. Conway DL, Adkins WB, Schroeder B, Langer O. Isolated Oligohydromnios in the term pregnancy: is it a clinical entity? J Matern Fetal Med 1998; 7: 197 -200 .

12. Panting - Kemp A, Nguyen T, Chang E, Quillen E, Castro L. Idiopathic polyhydramnios and perinatal outcome. Am J Obstet Gynecol 1999; 181: 1079 1082.

13. Smith CV, Plambeck RD, Raybum WF, Albaugh KJ. Relationship of mild idiopathic polyhydramnios to perinatal outcome. Obstet Gynecol 1992; 79(3):387 - 389 .
14. Kung - Chao Chen, Jui - Der Liou, Tai - Ho Hung, Dong - Ming Kuo, Jenn - Jeih Hsu, Ching - Chang Hsieh, T'sang - T'ang Hsieh. Perinatal outcomes of polyhydramnios without Associated Congenital fetal Anomalies after the Gestational Age of 20 weeks. Chang Gung Med J 2005 April; 28(4): 22 - 228.

15. Dorleijn DM, Cohen - Overbeek TE, Groenendaal F, Bruinse HW, Stoutenbeek P. Idiopathic Polyhydromnios and postnatal findings. J Matern Fetal Neonatal Med 2009 Apr; 22(4): 315 - 20.

16. Maliha Sadaf, Sobia Nawaz Malik, Jehan Ara, Sadaf Tufail, Shagufta Saeed Sail. Perinatal Outcome in Explained and Unexplained Polyhydromnios. Journal of Rawalpindi medical College (JRMC) 2013; 17(1): $104-106$.

17. Lawrence Leeman, David Almond. Isolated Oligohydramnias at term: Is induction indicated? Journal of Family Prectice 2005 Jan; 54(1):25 - 32.

18. Fozia Umber Qureshi, Ahmed Wasim Yusuf. Intravenous Amino Acids in Third Trimester isolated Oligohydramnios. Annals of King Edward medical University 2011; 17(2): 140 - 144.

19. Patrelli TS, Gizzo S, Cosmi E, Carpano MG, Dj Gangi S, Piantelli G, Modena AB. Maternal hydration therapy improves the quantity of Amniotic Fluid and pregnancy outcome in third trimester Isolated Oligohydramnios: A controlled randomized institutional trail. J Ultrasound Med 2012 Feb;31(2):239 - 244.

DOI: $10.5455 / 2320-1770 . i j r \operatorname{cog} 20131217$

Cite this article as: Manikanta Reddy V, Senthil

Kumar S, Sanjeeva Reddy N. Birth weight and term of the gestation in pregnancies complicated by isolated oligo and isolated polyhydramnios. Int $\mathrm{J}$ Reprod Contracept Obstet Gynecol 2013;2:577-80. 